\title{
A review of cutaneous lupus erythematosus: improving outcomes with a multidisciplinary approach
}

This article was published in the following Dove Press journal:

Journal of Multidisciplinary Healthcare

\author{
Paul Jarrett $\mathbb{D}^{1,2}$ \\ Victoria P Werth ${ }^{3,4}$ \\ 'Department of Dermatology, \\ Middlemore Hospital, Auckland, New \\ Zealand; ${ }^{2}$ Department of Medicine, The \\ University of Auckland, Auckland, New \\ Zealand; ${ }^{3}$ Corporal Michael J. Crescenz \\ Veteran Affairs Medical Center, \\ Philadelphia, PA, USA; ${ }^{4}$ Department of \\ Dermatology, University of Pennsylvania, \\ Philadelphia, PA, USA
}

\begin{abstract}
Cutaneous lupus erythematosus encompasses a spectrum of cutaneous disease with different phenotypes, and it potentially intersects with many disciplines in medicine. This review examines the epidemiology, clinical subtypes, pathology, psychology and intervention options for this disorder. It is important to understand the psychological distress that cutaneous lupus can cause and if needed actively investigate this possibility with the patient. Careful liaison between disciplines will achieve the optimum outcome.
\end{abstract}

Keywords: epidemiology, definitions, subtypes, pathology, psychology, treatment

\section{Introduction}

Cutaneous lupus erythematosus (CLE) is an exemplar of a disorder requiring a multidisciplinary approach for its management. It has the potential to intersect with many disciplines and each can contribute to providing the optimum outcome for patients. The disciplines range from the basic sciences through to different organ-specific clinical specialties.

CLE has a surprising variety of clinical phenotypes. Therefore, a dermatologist is often the key facilitator for the primary diagnosis with referrals deriving from different disciplines. The subsequent management can take multiple and diverse pathways. Close and coordinated cooperation is important, and an understanding of cutaneous lupus by nondermatologists is helpful. This review examines the epidemiology, clinical subtypes, pathology, psychology and intervention options for this often disfiguring and distressing disorder.

\section{Definitions of CLE}

The Systemic Lupus International Collaborating Clinics (SLICC) criteria ${ }^{1}$ integrates the cutaneous manifestations of lupus with other the systemic features and is an alternative to the American College of Rheumatology classification. ${ }^{2}$ SLICC provides a long-needed unified and validated multidisciplinary classification criteria. The clinical mucocutaneous criteria of the SLICC classification are summarized in Table 1. The other clinical and immunological criteria of the SLICC classification are synovitis, serositis, renal, neurologic, hemolytic anemia, leukopenia, thrombocytopenia and immunologic (elevated ANA, anti-dsDNA, anti-Sm, antiphospholipid antibodies, low complement, direct Coombs test [in the absence of hemolytic anemia]). For the purposes of defining systemic lupus erythematosus (SLE), the patient
Correspondence: Paul Jarrett

Department of Dermatology, Middlemore Hospital, Module 7, Manukau Superclinic, PO Box 98743, Manukau 2240, Auckland New Zealand

Tel +6492760000

Fax +6492760282

Email Paul.Jarrett@middlemore.co.nz 
Table I Mucocutaneous features of lupus from the Systemic Lupus International Collaborating Clinics (SLICC) classification

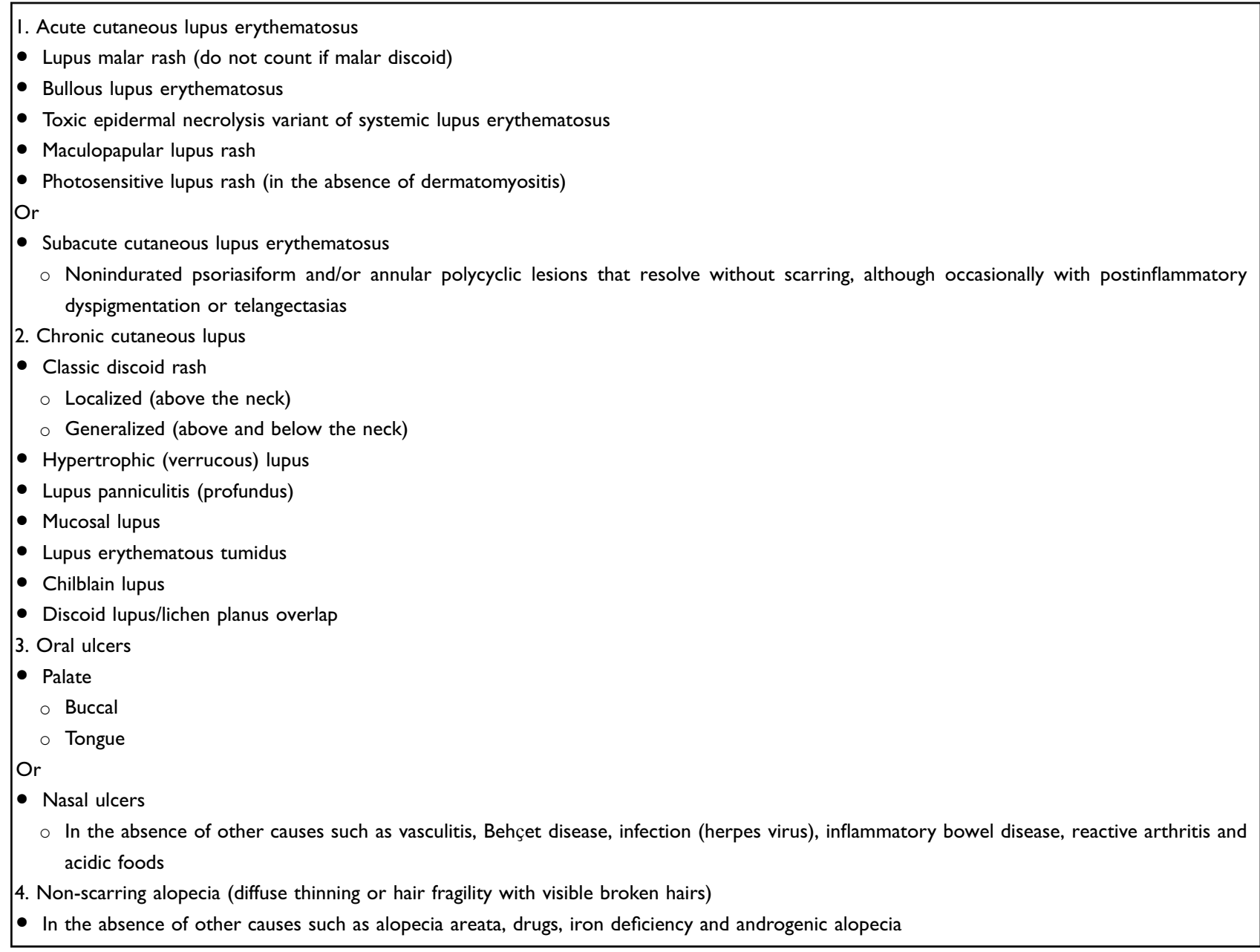

must satisfy four criteria, including at least one clinical and one immunologic, or have biopsy-proven lupus nephritis in the presence of antinuclear antibodies or anti-dsDNA antibodies. However, in the dermatology clinic, it is possible to make a diagnosis of CLE in the absence of any features of SLE or with only some but not all of the features needed to define SLE. Furthermore, occasionally, it can be difficult to exactly define into which subcategory of CLE to place a patient when there are overlapping clinical features.

\section{Epidemiology}

There are only a few population-based estimates of the prevalence and incidence of CLE and its ethnic variation. The available data do demonstrate consistency. In Olmstead County, Minnesota, USA, the prevalence of all types of cutaneous lupus was 73.24 (95\% CI 58.29-88.19) per $100,000 .^{3}$ This population was not representative of the United States as a whole with a $89.9 \%$ white population. However, this figure is close to that found in South
Auckland, New Zealand, with a prevalence of 86.0 (95\% CI 78.1-94.7) per 100,000 using a capture-recapture technique which accounts for unidentified cases by examining different but overlapping databases. ${ }^{4}$ The age- and sexadjusted relative risk (RR) of all types of CLE in Māori/ Pacific compared to the European population in South Auckland was 2.47 (95\% CI 3.06-3.67), suggesting that this group is predisposed to CLE. The population of South Auckland, New Zealand, of approximately 530,000 is diverse, with Māori and Pacific peoples forming 37\% of the population, New Zealand European/Other forming $38 \%$, and Asian forming $24 \%{ }^{5}$ The incidence of CLE in Olmstead County was 4.3 per 100,000 per year ${ }^{3}$ and in Sweden 4.0 per 100,000 per year ${ }^{6}$ Again these rates are consistent in two separate geographic populations, although ethnicity was not reported in the Swedish study.

Discoid lupus erythematosus (DLE) is consistently reported as the most common subtype, and this may be because as a chronic disorder, it is easier to identify compared 
to the more evanescent and non-scarring acute cutaneous and subacute cutaneous forms. Early in DLE, prior to scarring, it may be difficult to define the exact subtype of CLE. In the Olmstead study, the age- and sex-adjusted incidence rate per 100,000 for DLE was $3.56(95 \% \text { CI } 2.94-4.18)^{3}$ and in Auckland the prevalence rate of DLE per 100,000 for Māori/Pacific was 27.24 (95\% CI 20.73-35.82) compared to the European rate of 6.57 (95\% CI 3.76-11.49) ${ }^{4}$ The ageand sex-adjusted RR of DLE in Māori/Pacific was 5.96 (95\% CI 3.06-11.6) compared to the European population ${ }^{4}$ supporting the clinical impression that this group has a particular risk of DLE. In French Guiana, the crude average incidence of DLE was 3.56 per 100,000 per year. $^{7}$

In Stockholm County, Sweden, the incidence of subacute cutaneous lupus erythematosus (SCLE) was 0.7 per 100,000 per year and with a prevalence of $6.2-14$ per $100,000,{ }^{8}$ and this figure is consistent with Olmstead County reporting an incidence rate of $0.63(95 \% \mathrm{CI}$ $0.37-0.89$ ) per $100,000 .^{3}$

The other forms of CLE (hypertrophic, lupus panniculitis, mucosal, tumidus, chilblain and discoid lupus/lichen planus overlap) are unusual. For example, the incidence of lupus panniculitis and bullous lupus, respectively, is reported as $0.07(95 \%$ CI $0.00-0.16)$ and 0.03 (95\% CI $0.00-0.08)$, respectively. ${ }^{3}$

It has long been observed that SLE is more common in patients, with skin of color and those with Afro-Caribbean ${ }^{9}$ and African American ${ }^{10}$ ethnicity being at risk. In the Pacific region, in the US state of Hawaii, SLE is common in "part Hawaiians" compared to other ethnicities ${ }^{11}$ and in Auckland, New Zealand, more common in "Polynesians" compared to other groups. ${ }^{12}$ This has also been observed in DLE ${ }^{13}$ and is supported by the epidemiology from Auckland. As with many autoimmune diseases, CLE is consistently more common in women compared to men. ${ }^{3,4,7,8}$

\section{Clinical subtypes}

Examples of the three most common subtypes are shown in Figure 1. Acute cutaneous lupus erythematosus (ACLE) (Figure 1A) is typified by a malar rash, SCLE (Figure 1B) with a non-indurated psoriasiform and/or annular polycyclic rash and DLE (Figure 1C) with discoid lesions which when active are erythematous and scaling with follicular hyperkeratosis and resolve with scarring, including scarring alopecia (Figure 2) and postinflammatory hyper- or
A

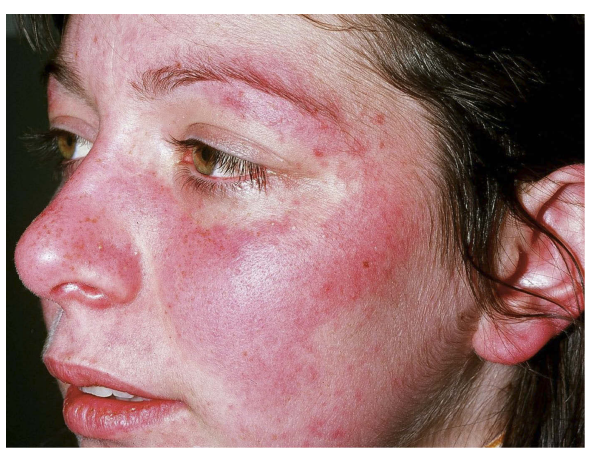

B

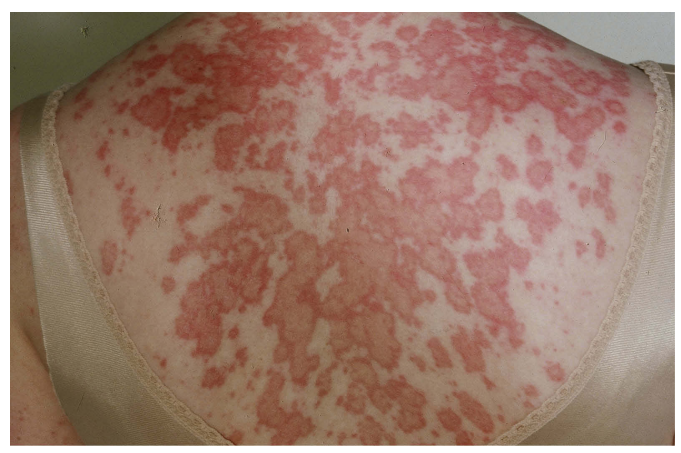

C

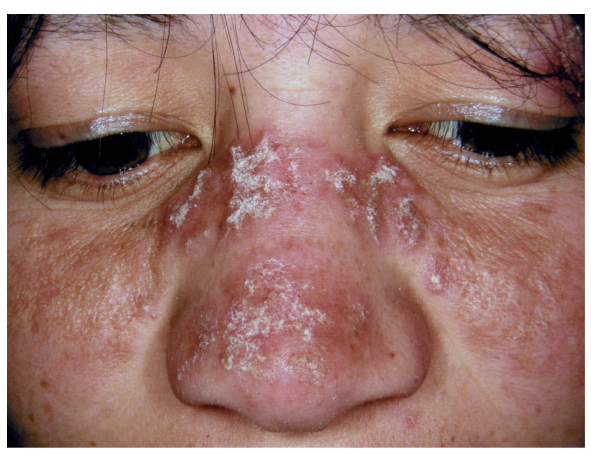

Figure I Acute cutaneous lupus erythematosus (A), subacute cutaneous lupus erythematosus (B), discoid lupus erythematosus (C).

Note: (A), (B) and (C) With permission from and courtesy of DermNet NZ. 


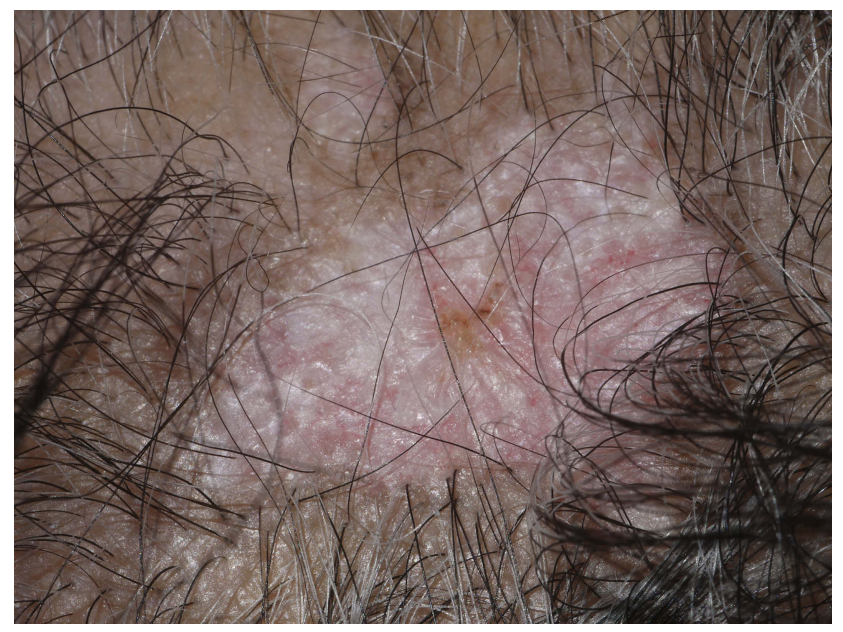

Figure 2 Scarring alopecia due to "burnt-out" discoid lupus erythematosus. Note: With permission from and courtesy of DermNet NZ.

hypopigmentation. Table 1 gives greater detail of the different types of acute and chronic cutaneous lupus.

\section{The relationship between cutaneous and systemic lupus erythematosus}

CLE may be part of the spectrum of SLE or be an entity alone with no systemic features. When part of SLE, CLE may undergo flares in the absence of any other systemic exacerbation or can be part of a multiorgan flare. ACLE is often part of SLE, but by contrast, DLE is commonly the only manifestation of lupus and is often ANA negative. SCLE was first defined by "mild systemic illness marked by musculoskeletal complaints and serologic abnormalities". ${ }^{14}$ SCLE is commonly ANA and Ro positive. ${ }^{15}$ In Finland, 24\% of patients with CLE were already diagnosed with SLE, and during a 2-3 year period an additional $18 \%$ were diagnosed with SLE and the group with the highest probability of having an additional SLE diagnosis was that with SCLE. ${ }^{6}$ With the introduction of the SLICC criteria, those with SLE/SCLE were more likely to have oral ulcers, positive dsDNA, positive ANA and low complement compared to those with SCLE only. ${ }^{16}$ The onset or concurrence of SLE mandates the involvement of other disciplines depending on organ involvement.

\section{Cutaneous pathology}

The clinical diagnosis of CLE is often supplemented by a skin biopsy so a good working relationship with a dermatopathologist is essential. In common with other skin diseases, the histological pattern evolves over time. The different types of CLE share similar and overlapping pathological features to a greater or lesser extent including epidermal vacuolization, apoptosis, an interface dermatitis, periappendageal (including papillary and reticular dermis) inflammation, follicular plugging, basement membrane thickening and dermal mucin. ${ }^{17}$ A description of a fully developed lesion of DLE serves as a pathological "template", and in such a lesion there is involvement of the epidermis, dermis and hair follicles including epidermal hyperkeratosis, vacuolization and apoptosis of the basal cells with variable epidermal hyperplasia and focal atrophy, an interface dermatitis of the epidermis and hair follicles accompanied by a patchy perivascular and periappendegeal lymphocytic infiltrate in the upper and lower dermis. The dermoepidermal and follicular basement membrane may be thickened. There are follicular keratin plugs, and extracellular mucin is deposited in the dermis. ${ }^{17}$

DLE typically scars, and this may be due to the involvement of the bulge area of the hair follicles where stem cells reside and to differences in remodeling of the basement membrane in DLE compared to other forms of lupus. ${ }^{18,19}$

\section{Pathophysiology}

The precise molecular mechanisms for the pathophysiology of cutaneous lupus are not clear. Cutaneous lupus is a photosensitive rash. There may be a genetic predisposition for some forms and drugs can provoke the eruption.

\section{Photosensitivity}

CLE is frequently a photosensitive eruption that can be induced by both ultraviolet A (UVA) and ultraviolet B (UVB) light. In patients with DLE, SCLE and SLE, the action spectrum of induced lesions was in UVB range in 33\%, in UVA range in $14 \%$ and in both UVA and UVB in $53 \% .^{20}$

Ro is a small ribonucleoprotein found mainly in the cell nucleus. The Ro antigen as determined by the presence of anti-Ro antibodies in SCLE and SLE may be important in the pathogenesis of lupus. Homologs of the Ro gene exist in many species and homologs are preserved where the gene product is useful for an organism, but they may be adapted. An example is the eubacterium Deinococcus radiodurans which is resistant to DNA-damaging agents, and in this organism the Ro homolog is important in resisting UVinduced damage. ${ }^{21}$ Therefore, it is interesting that humancultured keratinocytes irradiated with narrowband UVB (311 
$\mathrm{nm}$ ) lead to the externalization of "bleb"-like protrusions on the cell surface expressing La and Ro $60 \mathrm{kDa}$ antigens. ${ }^{84,85}$

\section{Genetics}

The genetics of cutaneous lupus is complex and not well understood. Using gene microarray technology to investigate global patterns of gene expression, prominent apoptosis and interferon response signals were found. ${ }^{22}$ Studies of the genetics of DLE show that variants in the integrin subunit alpha $\mathrm{M}$ gene (a member of the immune complex processing pathway) were highly significantly associated with patients who had DLE in the absence of systemic disease. ${ }^{23}$ Tyrosinase kinase 2 and interferon regulatory factor 5 polymorphisms are associated with discoid and SCLE. $^{24}$

\section{Immunopathology}

Interferon type 1 is central in the pathogenesis of lupus. ${ }^{25}$ Plasmacytoid dendritic cells are important in the pathogenesis of lupus via the production of type 1 interferon. ${ }^{26}$ There are two distinct patterns of immunostaining for these cells in the skin of patients with CLE, within the perivascular inflammation of the dermis and also at the dermoepidermal junction in association with cytotoxic $\mathrm{T}$ cells in areas of severe epithelial damage ${ }^{27}$ These cutaneous plasmacytoid dendritic cells strongly produce type I interferons. Furthermore, moving from the laboratory to the patient, the level of type I interferon gene expression in patients with CLE correlated with the disease severity. ${ }^{28}$

\section{Vitamin D}

There is substantial interest in vitamin D beyond its wellrecognised effects on bone health including its role in CLE and its potential immunomodulating effects. The study of vitamin $\mathrm{D}$ and CLE is complicated by differing definitions of what level is normal and abnormal. In New Zealand, a country whose capital Wellington lies at latitude $41.3^{\circ}$ south, $>50 \mathrm{nmol} / \mathrm{L}$ (serum 25 -hydroxyvitamin $\mathrm{D}$ ) is regarded as equal to or above the recommended level by the Ministry of Health. ${ }^{29}$ There are reports of the activity of SLE being associated with lower vitamin D levels. ${ }^{30}$ Photoprotection is part of the advice given to patients with CLE. There are several publications examining the association of vitamin D levels and cutaneous lupus with the finding that low levels are not uncommon. ${ }^{31-36}$ Association does not prove causality. One study has assessed if vitamin D levels are related to the activity of cutaneous lupus as measured by a clinical scoring system called the Cutaneous Lupus Erythematosus
Disease Area and Severity Index (CLASI) ${ }^{37}$ which did not demonstrate an association. ${ }^{35}$ One study reports a benefit of vitamin D supplementation in cutaneous lupus in disease activity measured by the CLASI. ${ }^{38}$

\section{Drug-induced cutaneous lupus}

A full review of this topic is outside the scope of this review. However, there are many drugs that can induce SLE and some will induce CLE, especially SCLE. In a study of 88 cases of drug-induced SCLE the most likely causative classes of drugs were proton pump inhibitors, antihypertensives and antifungals with a female to male ratio of $9: 1 .^{39}$ A case-controlled study of 234 patients of patients with SCLE found that in the 6 months prior to the diagnosis the most increased odds ratios were for terbinafine, tumour necrosis factor $\alpha$ (TNF- $\alpha$ ) inhibitors, anti-epileptics and proton pump inhibitors. ${ }^{40}$ DLE is rarely induced by drugs, but TNF- $\alpha$ inhibitors, fluorouracil, capecitabine and nonsteroidal anti-inflammatory drugs have been recorded. ${ }^{41-43}$

\section{Psychology of CLE}

The psychological effects of CLE can be profound but especially with DLE which can lead to permanent scarring on the face and scarring alopecia. Twenty-four patients with DLE participated in a study of psychological functioning. ${ }^{44}$ There was a positive correlation between disease activity and depression $(p=0.05)$, but no correlation with scarring ( $p=0.21$ ). This study also used drawings to assess the patients' perception of their skin before and after their diagnosis of DLE. An example of such a drawing is shown in Figure 3. The study also demonstrated that there was no correlation between the patients' perception of their skin and the dermatologist's objective assessment emphasizing the need for the clinician not to make assumptions about how the patients perceive their DLE. A further and larger study of 50 patients with DLE ${ }^{45}$ examined the quality of life using the Dermatology Quality Life Index (DLQI) ${ }^{46}$ with the CLASI scoring system. The CLASI gives two scores, one for the disease activity and one for the scarring. This study demonstrated a correlation between CLASI activity and damage scores with DLQI, respectively, $p=0.013$ and $p=0.006$. Furthermore, the study analysis suggested that scarring is more closely associated with DLQI than DLE disease activity. Predictors of low quality of life in patients with DLE are female sex, being a current smoker and having lower socioeconomic status. ${ }^{47}$ 


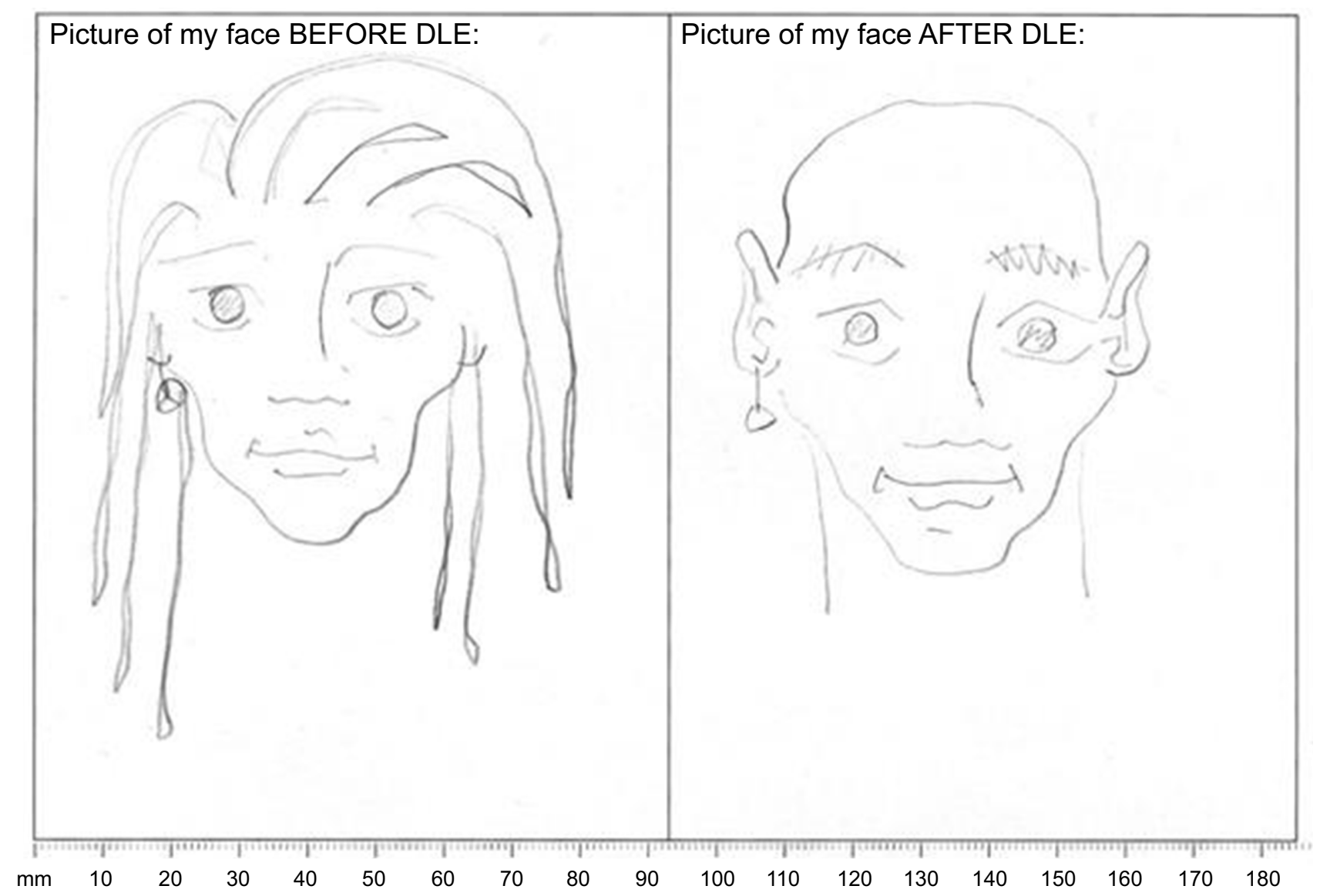

Figure 3 The patient's perception of their face before and after their diagnosis of discoid lupus erythematosus.

\section{Treatment}

When CLE forms part of significant systemic disease the skin will be treated "collaterally" and may not form the main problem in the context of other significant organ involvement. However, there are skin specific treatments, and especially in DLE every effort is needed to prevent irreversible scarring.

\section{Nonpharmacological therapy \\ Sun protection}

CLE is a photosensitive disorder and therefore sun protection is important. A habit of sun protection may not be intuitive for patients with skin of color who have CLE. ${ }^{48}$ Sun protection can be through appropriate clothing. The face is the most common site of CLE, and hat design is therefore important, especially the width of the brim. Peaked baseball caps protect the nose but are relatively ineffective at other sites. Hats with a wide brim $>7.5 \mathrm{~cm}$ are needed to provide reasonable protection around the nose and cheeks. ${ }^{49}$ Broad-spectrum sunblock providing both UVA and UVB protection should be used.
Approximately 2.5 fingertip units are needed, where one fingertip is the amount of cream expressed from a tube with a $5 \mathrm{~mm}$ diameter nozzle from the distal skin crease to the tip of the index finger, to effectively use sunblock to cover the face and neck. ${ }^{50}$ Sunblock needs to be reapplied depending on the outside activity undertaken. As discussed, vitamin D deficiency has been found in association with CLE, but empiric supplementation does not require vitamin D measurement and is safe.

\section{Smoking}

Cigarette smoking is associated with CLE. The odds ratio of smoking at the onset of DLE is 2.05 for DLE and for tumid lupus 4.5 in a study of 405 patients. ${ }^{51}$ Current smokers have worse disease, have worse quality of life and are more often treated with a combination of hydroxychloroquine and quinacrine compared to nonsmokers. ${ }^{52,53}$ Furthermore, smoking is associated with loss of efficacy of hydroxychloroquine (see the section "Pharmacological therapy") with a twofold decrease in the proportion of patients with CLE achieving cutaneous improvement. ${ }^{54}$ This may be due to enhancing 
Toll-like receptor-9 responsiveness and type I interferon production by plasmacytoid dendritic cells. ${ }^{55,56}$

\section{Withdrawal of medication inducing CLE}

Any suspected medication that may have induced CLE should be withdrawn. Possible drugs are discussed in the section "Drug-induced CLE.“

\section{Pharmacological therapy}

A comprehensive review of all treatments is not possible within the scope of this review. There are a number of excellent reviews. ${ }^{43,57-59}$ Treatment can be divided into topical, systemic and "other". Commonly topical and systemic treatments are used in tandem.

\section{Topical}

Topical steroids are the first line of treatment, especially for mild or focal disease. Potent or ultrapotent topical steroids should be used, and once-daily application is sufficient. The treatment of facial DLE is an indication for careful application of potent or ultrapotent steroids, but special care needs to be taken to avoid applying it to normal skin as the face is a risk area for the adverse effects. Mild topical steroids are less effective than potent steroids in the management of DLE. ${ }^{60}$ There are different formulations of topical steroids suitable for the scalp including foams, gels and liquids. Intralesional steroid injections such as triamcinolone acetonide can be useful for focal areas. Topical tacrolimus, a calcineurin inhibitor, is a useful alternative on the face as it does not produce the same adverse effects as ultrapotent topical steroids and is as effective. ${ }^{61}$ Pimecrolimus, a less potent calcineurin inhibitor, can also be used. ${ }^{62}$ There are also case reports of the use of topical retinoids including tretinoin, ${ }^{63}$ tazarotene ${ }^{64}$ and imiquimod. ${ }^{65}$ However, caution is needed with imiquimod as it has also been reported as inducing CLE. ${ }^{66-68}$ The use of R-salbutamol, which has anti-inflammatory properties, is also reported in two studies. ${ }^{69,70}$

\section{Systemic}

For severe disease and where topical agents are ineffective, systemic agents should be considered and used with a detailed risk-benefit analysis, as each brings its own potential side effect profile. Systemic steroids are effective for short-term control but are not a long-term option and do not work well in DLE. Antimalarial agents are first line and include hydroxychloroquine, chloroquine and quinacrine (mepacrine). Other systemic treatments are methotrexate, mycophenolate mofetil, dapsone, systemic retinoids (isotretinoin, alitretionin, acitretin), thalidomide, lenalidomide, ciclosporin, cyclophosphamide and biologic agents. A stepwise algorithm progressing from topical to systemic agents is useful, but not all agents are available in every country. ${ }^{57}$ Combinations of systemic treatments are commonly used.

Intravenous immunoglobulins may be beneficial with several studies supporting their use $\mathrm{s}^{71-74}$ and in pediatric disease. $^{75}$

The role of biologic therapies in the management of CLE is uncertain but an area of interest and current research. Potential targets include the B cell (rituximab and belimumab), the T cell (CTLA4-Ig), transcription factors involved in immune cell development (thalidomide derivatives), the plasmacytoid dendritic cell, JAK/stat pathway inhibition or cytokine inhibition including interferon- $\alpha$ (sifalimumab, anifrolumab), IL-6 (sirukumab, tocilizumab) and IL-12/23 (ustekinumab) ${ }^{76}$

\section{Other interventions for cutaneous lupus Phototherapy (UV light-I and lasers)}

It seems counterintuitive that light may be used to treat a light-sensitive disorder, and the exact mode of action is uncertain. Low-dose long-wave UVA (340-400 nm) may be effective in SLE as it has immunomodulatory effects ${ }^{77}$ and has been used successfully in two cases of DLE. ${ }^{78}$ There are case reports of the use of pulsed dye lasers (585-595 nm) in the treatment of CLE (DLE, SCLE and tumid lupus) in adults ${ }^{79-81}$ and DLE in a child, ${ }^{82}$ but this modality of treatment is not routine.

\section{Cryotherapy}

There is one case report of the use of cryotherapy to treat DLE on the arms, shoulders and back that had not responded to systemic steroids, antimalarials, azathioprine, dapsone and etretinate. ${ }^{83}$

\section{Psychological intervention}

It is important not to forget the benefit of simple measures such as the use of wigs in extreme alopecia and cosmetic camouflage to hide facial scarring given the potential for profound psychological disturbance. ${ }^{44,45}$ In the presence of significant psychological distress or depression, referral to psychology or psychiatry would be appropriate. 


\section{Conclusion}

Although the dermatologist is often the key health professional in making the diagnosis of CLE, this review demonstrates the multidisciplinary nature of this disorder. CLE intersects with many disciplines including epidemiology, general medicine, nephrology, rheumatology, family medicine, basic sciences, pharmacology, psychiatry and psychology. Patients expect the best outcome possible for this disorder so close cooperation in the setting of a combined multidisciplinary clinic provides the optimum setting to manage these often complex patients.

\section{Acknowledgments}

The authors gratefully acknowledge DermNet NZ for granting the permission to use the clinical images in this study. This work was partially supported by the United States Department of Veterans Affairs (Veterans Health Administration, Office of Research and Development and Biomedical Laboratory Research and Development) and NIH (National Institute of Arthritis and Musculoskeletal and Skin Diseases) R01AR071653 to VPW.

\section{Disclosure}

The authors report no conflicts of interest in this work.

\section{References}

1. Petri M, Orbai AM, Alarcon GS, et al. Derivation and validation of the systemic lupus international collaborating clinics classification criteria for systemic lupus erythematosus. Arthritis Rheum. 2012;64 (8):2677-2686. doi:10.1002/art.34473

2. Tan EM, Cohen AS, Fries JF, et al. The 1982 revised criteria for the classification of systemic lupus erythematosus. Arthritis Rheum. 1982;25(11):1271-1277.

3. Durosaro O, Davis MD, Reed KB, Rohlinger AL. Incidence of cutaneous lupus erythematosus, 1965-2005: a population-based study. Arch Dermatol. 2009;145(3):249-253. doi:10.1001/archdermatol.2009.21

4. Jarrett P, Thornley S, Scragg R. Ethnic differences in the epidemiology of cutaneous lupus erythematosus in New Zealand. Lupus. 2016;25 (13):1497-1502. doi:10.1177/0961203316651745

5. Population Profile. Available from: https:/countiesmanukau.health.nz/ about-us/our-region/population-profile/. Accessed December 21, 2018.

6. Gronhagen CM, Fored CM, Granath F, Nyberg F. Cutaneous lupus erythematosus and the association with systemic lupus erythematosus: a population-based cohort of 1088 patients in Sweden. Br J Dermatol. 2011;164(6):1335-1341. doi:10.1111/j.1365-2133.2011.10272.x

7. Deligny C, Clyti E, Sainte-Marie D, et al. Incidence of chronic cutaneous lupus erythematosus in French Guiana: a retrospective population-based study. Arthritis Care Res (Hoboken). 2010;62 (2):279-282. doi:10.1002/acr.20079

8. Popovic K, Nyberg F, Wahren-Herlenius M, Nyberg F. A serology-based approach combined with clinical examination of 125 Ro/SSA-positive patients to define incidence and prevalence of subacute cutaneous lupus erythematosus. Arthritis Rheum. 2007;56 (1):255-264. doi:10.1002/art.22286
9. Danchenko N, Satia JA, Anthony MS. Epidemiology of systemic lupus erythematosus: a comparison of worldwide disease burden. Lupus. 2006;15(5):308-318. doi:10.1191/0961203306lu2305xx

10. Stojan G, Petri M. Epidemiology of systemic lupus erythematosus: an update. Curr Opin Rheumatol. 2018;30(2):144-150. doi:10.1097/ BOR.0000000000000480

11. Serdula MK, Rhoads GG. Frequency of systemic lupus erythematosus in different ethnic groups in Hawaii. Arthritis Rheum. 1979;22(4):328-333.

12. Hart HH, Grigor RR, Caughey DE. Ethnic difference in the prevalence of systemic lupus erythematosus. Ann Rheum Dis. 1983;42 (5):529-532.

13. Callen JP. Chronic cutaneous lupus erythematosus. Clinical, laboratory, therapeutic, and prognostic examination of 62 patients. Arch Dermatol. 1982;118(6):412-416.

14. Sontheimer RD, Thomas JR, Gilliam JN. Subacute cutaneous lupus erythematosus: a cutaneous marker for a distinct lupus erythematosus subset. Arch Dermatol. 1979;115(12):1409-1415.

15. Deng JS, Sontheimer RD, Gilliam JN. Relationships between antinuclear and anti-Ro/SS-A antibodies in subacute cutaneous lupus erythematosus. J Am Acad Dermatol. 1984;11(3):494-499.

16. Tiao J, Feng R, Carr K, Okawa J, Werth VP. Using the American College of Rheumatology (ACR) and Systemic Lupus International Collaborating Clinics (SLICC) criteria to determine the diagnosis of systemic lupus erythematosus (SLE) in patients with subacute cutaneous lupus erythematosus (SCLE). J Am Acad Dermatol. 2016;74 (5):862-869. doi:10.1016/j.jaad.2015.12.029

17. Baltaci M, Fritsch P. Histologic features of cutaneous lupus erythematosus. Autoimmun Rev. 2009;8(6):467-473. doi:10.1016/j. autrev.2008.12.014

18. Al-Refu K, Edward S, Ingham E, Goodfield M. Expression of hair follicle stem cells detected by cytokeratin 15 stain: implications for pathogenesis of the scarring process in cutaneous lupus erythematosus. $\quad \mathrm{Br} \quad J \quad$ Dermatol. 2009;160(6):1188-1196. doi:10.1111/j.1365-2133.2009.09074.x

19. Al-Refu K, Goodfield M. Immunohistochemistry of ultrastructural changes in scarring lupus erythematosus. Clin Exp Dermatol. 2011;36(1):63-68. doi:10.1111/j.1365-2230.2010.03859.x

20. Lehmann P, Holzle E, Kind P, Goerz G, Plewig G. Experimental reproduction of skin lesions in lupus erythematosus by UVA and UVB radiation. J Am Acad Dermatol. 1990;22(2 Pt 1):181-187.

21. Chen X, Quinn AM, Wolin SL. Ro ribonucleoproteins contribute to the resistance of Deinococcus radiodurans to ultraviolet irradiation. Genes Dev. 2000;14(7):777-782.

22. Sinha AA, Dey-Rao R. Genomic investigation of lupus in the skin. J Investig Dermatol Symp Proc. 2017;18(2):S75-S80. doi:10.1016/j. jisp.2016.09.002

23. Jarvinen TM, Hellquist A, Koskenmies S, et al. Polymorphisms of the ITGAM gene confer higher risk of discoid cutaneous than of systemic lupus erythematosus. PLoS One. 2010;5(12):e14212. doi:10.1371/journal.pone.0014212

24. Jarvinen TM, Hellquist A, Koskenmies S, et al. Tyrosine kinase 2 and interferon regulatory factor 5 polymorphisms are associated with discoid and subacute cutaneous lupus erythematosus. Exp Dermatol. 2010;19(2):123-131. doi:10.1111/j.16000625.2009.00982.x

25. Pascual V, Farkas L, Banchereau J. Systemic lupus erythematosus: all roads lead to type I interferons. Curr Opin Immunol. 2006;18 (6):676-682. doi:10.1016/j.coi.2006.09.014

26. Farkas L, Beiske K, Lund-Johansen F, Brandtzaeg P, Jahnsen FL. Plasmacytoid dendritic cells (natural interferon- alpha/beta-producing cells) accumulate in cutaneous lupus erythematosus lesions. Am J Pathol. 2001;159(1):237-243.

27. Vermi W, Lonardi S, Morassi M, et al. Cutaneous distribution of plasmacytoid dendritic cells in lupus erythematosus. Selective tropism at the site of epithelial apoptotic damage. Immunobiology. 2009;214(9-10):877-886. doi:10.1016/j.imbio.2009.06.013 
28. Braunstein I, Klein R, Okawa J, Werth VP. The interferon-regulated gene signature is elevated in subacute cutaneous lupus erythematosus and discoid lupus erythematosus and correlates with the cutaneous lupus area and severity index score. Br J Dermatol. 2012;166 (5):971-975. doi:10.1111/j.1365-2133.2012.10825.x

29. Vitamin D Status of New Zealand Adults. Findings from the 2008/09 New Zealand Adult Nutrition Survey. 14 March 2012. ed2012. doi:10.1094/PDIS-11-11-0999-PDN

30. Singh A, Kamen DL. Potential benefits of vitamin D for patients with systemic lupus erythematosus. Dermatoendocrinol. 2012;4 (2):146-151. doi:10.4161/derm.20443

31. Cusack C, Danby C, Fallon JC, et al. Photoprotective behaviour and sunscreen use: impact on vitamin D levels in cutaneous lupus erythematosus. Photodermatol Photoimmunol Photomed. 2008;24 (5):260-267. doi:10.1111/j.1600-0781.2008.00373.x

32. Renne J, Werfel T, Wittmann M. High frequency of vitamin D deficiency among patients with cutaneous lupus erythematosus. $\mathrm{Br} J$ Dermatol. 2008;159(2):485-486. doi:10.1111/j.1365-2133.2008.08632.x

33. Heine G, Lahl A, Muller C, Worm M. Vitamin D deficiency in patients with cutaneous lupus erythematosus is prevalent throughout the year. Br J Dermatol. 2010;163(4):863-865. doi:10.1111/j.13652133.2010.09948.x

34. Cutillas-Marco E, Morales-Suarez-Varela M, Marquina-Vila A, Serum GW. 25-hydroxyvitamin D levels in patients with cutaneous lupus erythematosus in a Mediterranean region. Lupus. 2010;19 (7):810-814. doi:10.1177/0961203309360807

35. Word AP, Perese F, Tseng LC, Adams-Huet B, Olsen NJ, Chong BF. 25Hydroxyvitamin D levels in African-American and Caucasian/Hispanic subjects with cutaneous lupus erythematosus. Br J Dermatol. 2012;166 (2):372-379. doi:10.1111/j.1365-2133.2011.10667.x

36. Gronhagen CM, Tang MB, Tan VW, Tan KW, Lim YL. Vitamin D levels in 87 Asian patients with cutaneous lupus erythematosus: a case-control study. Clin Exp Dermatol. 2016;41(7):723-729. doi:10.1111/ced.12884

37. Albrecht J, Taylor L, Berlin JA, et al. The CLASI (Cutaneous Lupus Erythematosus Disease Area and Severity Index): an outcome instrument for cutaneous lupus erythematosus. $J$ Invest Dermatol. 2005;125(5):889-894. doi:10.1111/j.0022-202X.2005.23889.x

38. Cutillas-Marco E, Marquina-Vila A, Grant WB, Vilata-Corell JJ, Morales-Suarez-Varela MM. Vitamin D and cutaneous lupus erythematosus: effect of vitamin D replacement on disease severity. Lupus. 2014;23(7):615-623. doi:10.1177/0961203314522338

39. Laurinaviciene R, Sandholdt LH, Bygum A. Drug-induced cutaneous lupus erythematosus: 88 new cases. Eur J Dermatol. 2017;27 (1):28-33. doi:10.1684/ejd.2016.2912

40. Gronhagen CM, Fored CM, Linder M, Granath F, Nyberg F. Subacute cutaneous lupus erythematosus and its association with drugs: a population-based matched case-control study of 234 patients in Sweden. Br J Dermatol. 2012;167(2):296-305. doi:10.1111/ j.1365-2133.2012.10969.x

41. Vedove CD, Del Giglio M, Schena D, Girolomoni G. Drug-induced lupus erythematosus. Arch Dermatol Res. 2009;301(1):99-105. doi:10.1007/s00403-008-0895-5

42. He Y, Sawalha AH. Drug-induced lupus erythematosus: an update on drugs and mechanisms. Curr Opin Rheumatol. 2018;30(5):490-497. doi:10.1097/BOR.0000000000000522

43. Kuhn A, Aberer E, Bata-Csorgo Z, et al. S2k guideline for treatment of cutaneous lupus erythematosus - guided by the European Dermatology Forum (EDF) in cooperation with the European Academy of Dermatology and Venereology (EADV). J Eur Acad Dermatol Venereol. 2017;31(3):389-404. doi:10.1111/jdv.14053

44. Chen P, Broadbent E, Coomarasamy C, Jarrett P. Illness perception in association with psychological functioning in patients with discoid lupus erythematosus. $B r \quad J$ Dermatol. 2015;173(3):824-826. doi:10.1111/bjd.13709
45. Gordon H, Chandran A, Vandal AC, Yung A, Jarrett P. The relationship between disease severity and quality of life in discoid lupus erythematosus. Br J Dermatol. 2017;177(4):1134-1135. doi:10.1111/ bjd. 15227

46. Finlay AY, Khan GK. Dermatology Life Quality Index (DLQI)-a simple practical measure for routine clinical use. Clin Exp Dermatol. 1994;19(3):210-216.

47. Teske NM, Cardon ZE, Ogunsanya ME, Li X, Adams-Huet B, Chong BF. Predictors of low quality of life in patients with discoid lupus. $\mathrm{Br}$ J Dermatol. 2017;177(4):e147-e149. doi:10.1111/bjd.15490

48. Yang SY, Bernstein I, Lin DQ, Chong BF. Photoprotective habits of patients with cutaneous lupus erythematosus. $J$ Am Acad Dermatol. 2013;68(6):944-951. doi:10.1016/j.jaad.2012.11.016

49. Diffey BL, Cheeseman J. Sun protection with hats. Br J Dermatol. 1992;127(1):10-12.

50. Long CC, Finlay AY. The finger-tip unit-a new practical measure. Clin Exp Dermatol. 1991;16(6):444- 447.

51. Bockle BC, Sepp NT. Smoking is highly associated with discoid lupus erythematosus and lupus erythematosus tumidus: analysis of 405 patients. Lupus. 2015;24(7):669-674. doi:10.1177/0961203314559630

52. Piette EW, Foering KP, Chang AY, et al. Impact of smoking in cutaneous lupus erythematosus. Arch Dermatol. 2012;148 (3):317-322. doi:10.1001/archdermatol.2011.342

53. Kuhn A, Sigges J, Biazar C, et al. Influence of smoking on disease severity and antimalarial therapy in cutaneous lupus erythematosus: analysis of 1002 patients from the EUSCLE database. Br J Dermatol. 2014;171(3):571-579. doi:10.1111/bjd.13006

54. Chasset F, Frances C, Barete S, Amoura Z, Arnaud L. Influence of smoking on the efficacy of antimalarials in cutaneous lupus: a meta-analysis of the literature.[Erratum appears in $\mathrm{J}$ Am Acad Dermatol. 2015 Aug;73(2):353]. J Am Acad Dermatol. 2015;72 (4):634-639. doi:10.1016/j.jaad.2014.12.025

55. Kwatra SG. Toll-like receptor-9 signaling and decreased efficacy of antimalarial drugs in smokers with cutaneous lupus erythematosus. J Am Acad Dermatol. 2015;73(2):e79. doi:10.1016/j.jaad.2015.04.068

56. Chasset F, Frances C, Arnaud L. Smoking enhances Toll-like receptor-9 responsiveness and type I interferon production in plasmacytoid dendritic cells in patients with cutaneous lupus erythematosus. J Am Acad Dermatol. 2015;73(2):e81. doi:10.1016/j. jaad.2015.05.023

57. Chang J, Werth VP. Therapeutic options for cutaneous lupus erythematosus: recent advances and future prospects. Expert Rev. 2016;12 (10):1109-1121.

58. Kuhn A, Ochsendorf F, Bonsmann G. Treatment of cutaneous lupus erythematosus. Lupus. 2010;19(9):1125-1136. doi:10.1177/ 0961203310370345

59. Hansen CB, Dahle KW. Cutaneous lupus erythematosus. Dermatol Ther. 2012;25(2):99-111. doi:10.1111/j.1529-8019.2012.01508.x

60. Roenigk HH Jr., Martin JS, Eichorn P, Gilliam JN. Discoid lupus erythematosus. Diagnostic features and evaluation of topical corticosteroid therapy. Cutis. 1980;25(3):281-285.

61. Tzung TY, Liu YS, Chang HW. Tacrolimus vs. clobetasol propionate in the treatment of facial cutaneous lupus erythematosus: a randomized, double-blind, bilateral comparison study. $B r J$ Dermatol. 2007;156 (1):191-192. doi:10.1111/j.1365-2133.2006.07595.x

62. Avgerinou G, Papafragkaki DK, Nasiopoulou A, Arapaki A, Katsambas A, Stavropoulos PG. Effectiveness of topical calcineurin inhibitors as monotherapy or in combination with hydroxychloroquine in cutaneous lupus erythematosus. J Eur Acad Dermatol Venereol. 2012;26(6):762-767. doi:10.1111/j.1468-3083.2011.04161.x

63. Seiger E, Roland S, Goldman S. Cutaneous lupus treated with topical tretinoin: a case report. Cutis. 1991;47(5):351-355.

64. Edwards KR, Burke WA. Treatment of localized discoid lupus erythematosus with tazarotene. J Am Acad Dermatol. 1999;41 (6):1049-1050. 
65. Gul U, Gonul M, Cakmak SK, Kilic A, Demiriz M. A case of generalized discoid lupus erythematosus: successful treatment with imiquimod cream 5\%. Adv Ther. 2006;23(5):787-792.

66. Burnett TJ, English JC 3rd, Ferris LK. Development of subacute cutaneous lupus erythematosus associated with the use of imiquimod to treat actinic keratoses. J Drugs Dermatol. 2010;9(8):1022-1024.

67. Jimenez-Gallo D, Brandao BJF, Arjona-Aguilera C, Baez-Perea JM, Linares-Barrios M. Imiquimod-induced cutaneous lupus erythematosus with antinuclear antibodies showing a homogenous pattern. Clin Exp Dermatol. 2017;42(7):795-797. doi:10.1111/ced.13174

68. Maguiness SM, Farsani TT, Zedek DC, Berger TG. Imiquimodinduced subacute cutaneous lupus erythematosus-like changes. Cutis. 2015;95(6):349-351.

69. Jemec GB, Ullman S, Goodfield M, et al. A randomized controlled trial of R-salbutamol for topical treatment of discoid lupus erythematosus. $\quad \mathrm{Br} \quad J \quad$ Dermatol. 2009;161(6):1365-1370. doi:10.1111/j.1365-2133.2009.09330.x

70. Wulf HC, Ullman S. Discoid and subacute lupus erythematosus treated with $0.5 \%$ R-salbutamol cream. Arch Dermatol. 2007;143 (12):1589-1590. doi:10.1001/archderm.143.12.1589

71. Genereau T, Chosidow O, Danel C, Cherin P, Herson S. High-dose intravenous immunoglobulin in cutaneous lupus erythematosus. Arch Dermatol. 1999;135(9):1124-1125.

72. Goodfield M, Davison K, Bowden K. Intravenous immunoglobulin (IVIg) for therapy-resistant cutaneous lupus erythematosus (LE). J Dermatolog Treat. 2004;15(1):46-50. doi:10.1080/ 09541440042000269

73. Kreuter A, Hyun J, Altmeyer P, Gambichler T. Intravenous immunoglobulin for recalcitrant subacute cutaneous lupus erythematosus. Acta Derm Venereol. 2005;85(6):545-547. doi:10.1080/00015550510037071

74. Lampropoulos CE, Hughes GR, Dc DP. Intravenous immunoglobulin in the treatment of resistant subacute cutaneous lupus erythematosus: a possible alternative. Clin Rheumatol. 2007;26(6):981-983. doi:10.1007/s10067-006-0222-5

75. Juhasz M, Rogge M, Chen M, Czernik A, Jung Kim S, Geller L. Case of pediatric bullous systemic lupus erythematosus treated with intravenous immunoglobulin. Pediatr Dermatol. 2017;34(1):e54-e56. doi:10.1111/ pde. 13015
76. Presto JK, Hejazi EZ, Werth VP. Biological therapies in the treatment of cutaneous lupus erythematosus. Lupus. 2017;26(2):115-118. doi:10.1177/0961203316670731

77. McGrath H Jr., Bak E, Michalski JP. Ultraviolet-A light prolongs survival and improves immune function in (New Zealand black x New Zealand white)F1 hybrid mice. Arthritis Rheum. 1987;30 (5):557-561.

78. Mitra A, Yung A, Goulden V, Goodfield MD. A trial of low-dose UVA1 phototherapy for two patients with recalcitrant discoid lupus erythematosus. Clin Exp Dermatol. 2006;31(2):299-300. doi:10.1111/j.1365-2230.2005.02030.x

79. Erceg A, Bovenschen HJ, van de Kerkhof PC, de Jong EM, Seyger MM. Efficacy and safety of pulsed dye laser treatment for cutaneous discoid lupus erythematosus. $J$ Am Acad Dermatol. 2009;60(4):626-632. doi:10.1016/j.jaad.2008.11.904

80. Gupta G, Roberts DT. Pulsed dye laser treatment of subacute cutaneous lupus erythematosus. Clin Exp Dermatol. 1999;24 (6):498-499.

81. Truchuelo MT, Boixeda P, Alcantara J, Moreno C, de Las Heras E, Olasolo PJ. Pulsed dye laser as an excellent choice of treatment for lupus tumidus: a prospective study. J Eur Acad Dermatol Venereol. 2012;26(10):1272-1279. doi:10.1111/j.1468-3083.2011. 04281.x

82. Yelamos O, Roe E, Baselga E, Puig L. Pediatric cutaneous lupus erythematosus treated with pulsed dye laser. Pediatr Dermatol. 2014;31(1):113-115. doi:10.1111/pde.12248

83. Molin L, Tarstedt M. Discoid lupus erythematosus treated with cryotherapy. J Dermatolog Treat. 2003;14(3):182-183.

84. Casciola-Rosen LA, Anhalt G, Rosen A. Autoantigens targeted in systemic lupus erythematosus are clustered in two populations of surface structures on apoptotic keratinocytes. J Exp Med. 1994;179 (4):1317-1330. doi:10.1084/jem.179.4.1317

85. Reich A, Meurer M, Viehweg A, Muller DJ. Narrow-band UVBinduced Externalization of Selected Nuclear Antigens in Keratinocytes: Implications for Lupus Erythematosus Pathogenesis. Photochem Photobiol. 2009;85(1):1-7 doi:10.1111/php.2009.85. issue-1

\section{Publish your work in this journal}

The Journal of Multidisciplinary Healthcare is an international, peerreviewed open-access journal that aims to represent and publish research in healthcare areas delivered by practitioners of different disciplines. This includes studies and reviews conducted by multidisciplinary teams as well as research which evaluates the results or conduct of such teams or healthcare processes in general. The journal covers a very wide range of areas and welcomes submissions from practitioners at all levels, from all over the world. The manuscript management system is completely online and includes a very quick and fair peer-review system. Visit http://www.dovepress.com/testimonials. php to read real quotes from published authors. 